\title{
Qualities Medical Students Most Value in Tutors
}

\author{
Laura Pattison $^{1}$ (D) $\cdot$ James Mason ${ }^{1} \cdot$ Anvay Deshpande ${ }^{1}$
}

Published online: 11 November 2019

(C) International Association of Medical Science Educators 2019

\section{Dear Editor,}

We are final year students on a graduate-entry medicine program in the UK. Our course features case-based learning (CBL), similar to problem-based learning, but with a clinical focus. We are great advocates for peer-assisted learning; our curriculum has been described as "four dimensional," with near-peer teaching initiatives comprising the fourth dimension [1]. However, thus far, we have not had near peers acting as CBL tutors, and so the study by Nagraj et al. on student views of different types of PBL tutors [2] is of great interest to us.

Nagraj et al. highlight the need to take account of variations among tutors and their individual skills. Evaluation questionnaires and feedback from our cohort revealed the top three qualities we value most in our CBL tutors:

1. "Insider knowledge" on the curriculum and exams

2. Being relatable

3. Allowing us autonomy

It is clear how near-peer tutors may satisfy these criteria more easily than staff tutors. Our near peers certainly have "insider knowledge," having recently sat the exams we are studying for, and therefore have greater legitimacy in steering us on how to pass. Secondly, they are inherently more relatable, and both serve as excellent role models and have a deeper understanding of what we are going through. Finally, as "adult learners," we crave the autonomy to decide for ourselves what is most helpful for us to spend valuable time on. A near-peer tutor, being of similar age and experience, is less likely to assume a paternalistic, didactic style of teaching, and thus foster greater engagement. Additionally, a more

Laura Pattison

Laura.pattison8@gmail.com

1 Warwick Medical School, Warwick University, Coventry CV4 7HL, UK trusting relationship with a near peer may facilitate selfdisclosure of areas of ignorance, enabling more effective learning [3].

However, as the authors emphasize, near-peer tutors still need rigorous training in order to overcome individual variations between them. In our cohort, 66\% (112/170) of students indicated that they would like to train as near-peer tutors. This surplus of interest allows for a selective recruitment process. We suggest the implementation of recruitment criteria incorporating the competencies and qualities discussed above, thus minimizing the variation from the outset, and making the task of achieving a more uniform approach through training more attainable.

The benefit for the tutors themselves is well known, as Socrates' professed "docendo descimus"-we learn by teaching. Having near-peer tutors certainly seems to be a win-win situation and one that we are now looking to implement at our school.

\section{Compliance with Ethical Standards}

Ethical Approval A statement for ethical approval is not applicable.

Informed Consent A statement for informed consent is not applicable. NA

Conflict of Interest The authors declare that they have no conflict of interest.

\section{References}

1. De Cates D, Owen K, Macdougall C. Warwick Medical School: a four dimensional curriculum. Med Teach. 2018;40(5):488-94.

2. Nagraj S, Miles S, Bryant P, Holland R. Medical students' views about having different types of problem-based learning tutors. Med Sci Educ. 2019;29:93-100. https://doi.org/10.1007/s40670-01800634-9.

3. Topping KJ. Trends in peer learning. Educ Psych. 2005;25:631-45.

Publisher's Note Springer Nature remains neutral with regard to jurisdictional claims in published maps and institutional affiliations. 